\title{
What is Wrong with Deductivism?
}

\section{LILIAN BERMEJO-LUQUE}

\author{
Department of Philosophy I \\ University of Granada \\ Edificio de Psicología, Campus de Cartuja. Granada 18001 \\ Spain \\ lilian.bermejoluque@gmail.com
}

\begin{abstract}
In "Deductivism as an Interpretative Strategy: A Reply to Groarke's Defense of Reconstructive Deductivism," David Godden (2005) distinguished two notions of deductivism. On the one hand, as an interpretative thesis, deductivism is the view that all-natural language argumentation must be interpreted as being deductive. On the other hand, as an evaluative thesis, deductivism is the view that for a conclusion to follow, it has to follow of necessity from the premises - or, in other words, that being a good inference implies being deductive. The main goal of this paper is to show that evaluative deductivism is wrong.
\end{abstract}

Résumé: Dans «Le déductivisme comme stratégie interprétative: une réponse à la défense de Groarke contre le déductivisme reconstructif», David Godden (2005) a distingué deux notions de déductivisme. D'une part, en tant que thèse interprétative, le déductivisme est l'idée que toute argumentation en langage naturel doit être interprétée comme étant déductive. À son tour, en tant que thèse évaluative, le déductivisme est l'idée que pour qu'une conclusion s'ensuive, elle doit nécessairement découler des prémisses - ou, en d'autres termes, qu'être une bonne inférence implique d'être déductive. L'objectif principal de cet article est de montrer que le déductivisme évaluatif est faux.

Keywords: evaluative deductivism, interpretative deductivism, linguistic normative model of argumentation (LNMA), inference vs. argument, types of inferences, normativity of inference

\section{Introduction}

In "Deductivism as an Interpretative Strategy: A Reply to Groarke's Recent Defense of Reconstructive Deductivism," David Godden (2005) distinguished two notions of deductivism. On the one hand, as an evaluative thesis, evaluative deductivism (D1) is 
the view that for a conclusion to follow, it has to follow of necessity from the premises - or, in other words, that being a good inference implies being deductive. On the other hand, as an interpretative thesis, interpretative deductivism (D2) is the view that all natural-language argumentation must be interpreted as being deductive. In that paper, Godden argued that evaluative deductivism is wrong and that, for this reason, interpretative deductivism must be grounded on something other than the claim that ' $q$ follows from p' means 'q necessarily follows from $p$.'

Despite Godden's remarkable observations in that paper, evaluative deductivism has proven to be difficult to refute. The reason is that its intuition on the meaning of 'follows' can always be saved by means of a straightforward strategy for rendering deductive any piece of argumentation - namely, to assume that it has an implicit conditional premise with, as its antecedent, the conjunction of the set of premises of the original argument and, as the consequent, its conclusion (which, in turn, may be qualified as required with modals such as presumably, likely, probably, etc.). Of course, such a strategy blurs the distinction between monotonic and nonmonotonic inferences, and it is also available for Bayesian inferences: all that is needed is the trivial conditional and the adequate modal for the conclusion. Accordingly, for the deductivist, pointing to these types of inferences would not show that deductivism is wrong.

The main goal of this paper is to show that evaluative deductivism is wrong. In order to do this, in sections 2 and 3, I build the following modus tollens: as Godden has argued, "the correctness of deductivism as an evaluative thesis can be invoked as a reason for its acceptability as an interpretative strategy. Clearly, if [D1] were true - that is, if the only acceptable standard of evidence was that embodied in the rules of deduction - then [D2] would follow as a consequence" (Godden, 2005, p. 170). Thus, by showing that interpretative deductivism is implausible, I will show that evaluative deductivism is wrong. My second goal is to explain why evaluative deductivism is wrong. Authors endorsing evaluative deductivism contend that the only possible standard of inference is to require the conclusion not to be wrong if the premises are right. In section 4 , I show that the model of inference that I defend in this 
paper accommodates this standard in a certain way without implying that deductive inferences are the only inferences that can be taken to be good. As I will point out, this alternative version of the standard of inference springs from the very notion of inference: what makes an inference good is constitutive of what an inference is, not a matter of conforming to standards that, on some more basic intuition, seem sound.

\section{The relationship between evaluative deductivism and inter- pretative deductivism}

As Godden pointed out:

D: if it is true that for a conclusion to follow it has to follow of necessity from the premises (evaluative deductivism), then it is plausible to interpret natural language and argumentation as deductive (interpretative deductivism)

$\mathrm{D}$ is the way in which deductivism affects our theories of how to interpret natural language argumentation and reasoning. For, in principle, as Godden observes, if evaluative deductivism were true, then we would have good reason to believe that individuals aim at making deductions - for, otherwise, they would not aim at arguing or reasoning well, which is implausible. Consequently, in order to properly represent what people mean when they argue or reason, we should render their inferences deductive, as far as possible.

Importantly, this is always possible. Certainly, people do not always reason or argue in a way in which what they put forward as their conclusion cannot be false if what they put forward as their premises is true; but we can always assume that their argumentation is enthymematic and reconstruct what they say so as to render their inferences deductive. This is then the way of understanding interpretative deductivism: in it, 'interpreting' does not really stand for 'understanding' but for 'reconstructing.'

Because we can always reconstruct inferences as being deductive, evaluative deductivism turns out to be a requirement to reconstruct all natural language argumentation and reasoning as deductive. This is why deductivists, such as Groarke, hold that the 
meaning of words like 'therefore,' 'so,' 'hence,' etc. announces the speaker's intention of making a deductively valid inference (Groarke, 1992, p. 114). Consequently, mainstream deductivism also endorses this conditional:

D': if for a conclusion to follow it has to follow of necessity from the premises (evaluative deductivism), then natural language argumentation must be interpreted as being deductive (interpretative deductivism)

Importantly, defending D and D' on this ground requires acknowledging that we build arguments as a means to represent natural language argumentation and reasoning. That is, arguments would be reconstructions from real things such as reasonings and pieces of natural language argumentation as they occur in everyday life. On the other hand, this line of defense of D and D' would also imply that being a deductive inference cannot be the same as being a good inference. After all, that people intend to infer well-which is the reason why, allegedly, we should interpret them as making deductions - should not imply that they get to infer well, on pain of making the task of appraising inferences pointless.

In a way, this was Copi's view (1978: p. 32) when he pointed out that deductiveness and validity are different notions. Yet, unless we are able to distinguish between the inferences that people actually make - which according to the deductivist are supposed to be deductive - and the arguments by means of which we represent them-which may represent good or bad inferences-we could not point to an instance of something that is both deductive and a bad inference. This is so because any set of propositions that stands for a deductive argument also stands for a valid argument. For this reason, authors like Berg (1987), Vorobej (1992), and Godden (2005) hold that whether an inference is deductive or not is a matter of the arguer's intentions. Specifically, an inference would be deductive if its conclusion is meant to follow of necessity; and if it actually does follow of necessity, then the inference will be not only deductive but also valid. 
Authors like Machina (1985) and Hitchcock (1980, 2017) disagree with this intentionalist notion of deductiveness. For example, Hitchcock says that:

(...) appeals to the intentions or claims or beliefs of reasoners and arguers are vacuous in many cases and are unnecessary for argument appraisal (...). As one can confirm for oneself by immediate retrospection, reasoners who draw a conclusion for themselves from information at their disposal are typically unaware of whether they are drawing it conclusively or non-conclusively. Reasoners just draw their conclusions, and it is only after that inferential act, if at all, that they determine whether their conclusion follows conclusively or non-conclusively. As for arguers, they sometimes claim a qualitative degree of support for their conclusion by qualifying it with terms like 'must' or 'probably' or 'presumably' or 'may.' But they do so in a minority of cases. (Hitchcock: 2017, p 252)

If we cannot discover an arguer's intentions in this respect, we must construe the argument as ambiguous and test it against both deductive and inductive (and conductive and...) standards. (Hitchcock, 2017, p. 5).

However, since interpretative deductivism urges us to take as part of the inference any premise needed in order to make the corresponding argument deductive, following Hitchcock's strategy on such ground would require us to reconstruct any inference as a deductively valid argument.

For my part, I agree with Berg, Vorobej, and Godden that we can only appraise an inference by considering what the subject means by it. Particularly, we have to take into account the way in which she means her conclusion to follow from her premises. For example, imagine someone saying, "John's car is in front of his home; so, he's at home," It is only by ascribing a certain epistemic force to their conclusion that we can say that their argumentation is good or bad: if we take them to mean that necessarily John is at home, we will say that their argumentation is bad; whereas if we take them to mean that presumably John is at home, we will say that their argumentation is good. At any rate, unless we attribute 
some intention in this respect to the speaker, we will not be in a position to appraise their argumentation. Notice that, for the deductivist, the latter would also be a deductive inference whose conclusion is "presumably, John is at home," which would follow necessarily from the premise "John's car is in front of his home" and the implicit premise "if John's car is in front of his home, then, presumably, he is at home" (Groarke, 1992, p. 115).

Among others, Govier (1992) and Godden (2005) have argued that we cannot add the conditional that makes explicit the inferential link between premises and conclusion as a premise because, as Lewis Carroll (1895) would have shown, this conditional does not play the same role as the other propositions of the inference. However, as Castañeda (1960) and Botting (2016) have observed, that premises and associated conditionals play different roles does not imply that we cannot reconstruct inferences as deductive arguments. For, as pointed out, arguments are mere reconstructions of the inferences that we make, and we build them in order to appraise the semantic properties of these inferences; if the model actually helps to determine whether the inference is good or bad, whether it does so by rendering the inference deductive is unimportant. Remarkably, if we think of interpretative deductivism as the thesis that we can reconstruct inferences as deductive in order to appraise them, then deductivism would be harmless. But, of course, this is not what interpretative deductivists contend: their claim is that we must reconstruct inferences as deductive in order to accurately represent what people mean when they infer because, in the deductivist's view, 'follows' means 'necessarily follows.' Thus, my next step is to present a theory of inference that is able to make sense of the two intuitions behind D and D'-namely, that we build arguments to represent the inferences that we make in arguing and reasoning, and that not all deductive inferences are valid - and still also able to relieve us from the obligation to reconstruct natural language argumentation and reasoning as deductive in order to properly represent what individuals mean when they aim at making good inferences. 


\section{Reasoning, argumentation, inferences, and arguments. The linguistic normative model of argumentation}

Within the framework of formal logic, an argument is usually defined as a set of propositions, one of which - the conclusion - follows from the others - the premises. But the problem with this definition is: if the premises of an argument do not follow from the conclusion, isn't such a set of propositions just a set of propositions? As Fohr $(1979$, p. 5) observed, the common usage of the term 'argument' - and the very business of appraising arguments - requires that there can be bad instances of it. This is why he recommends that we refrain from thinking of arguments as things that exist in vacuo, but instead think of them as being person-related (Fohr, 1979, p. 5).

In Bermejo-Luque (2011), I proposed a linguistic normative model of argumentation (LNMA) that captures Fohr's intuition that the best way of avoiding such problems is to adopt a pragmatic linguistic perspective able to abandon Platonism altogether, that is, the view that arguments as abstract entities exist so that people just use them when they argue or reason. LNMA follows Bach and Harnish's (1979) speech-act schema (SAS) in order to characterize argumentation as a second order speech-act complex, that is, as a speech-act composed of a speech-act of adducing (the reason, R) and a speech-act of concluding (the conclusion or target-claim, $\mathrm{T}$ ). Acts of adducing and acts of concluding are constatives, whether directly or indirectly performed, literal or non-literal; but they are second order because they can only be performed by means of first order constative speech-acts. According to this model, a performance of, for example, "I promise I'll take care, don't worry"which, in principle, involves just two first order speech-acts, that is, a promise and a request - turns into a speech-act complex of arguing because it turns these two first order speech-acts into the constative speech-act of adducing that the arguer commits herself to take care and the constative speech-act of concluding that the addressee should not worry, respectively.

Two speech-acts become an act of adducing $\mathrm{R}$ and an act of concluding $\mathrm{T}$ because of their relationship to an implicit inferenceclaim whose propositional content is "if $R$, then $T$." In a few 
words, it is by attributing to the speaker the implicit inferenceclaim "if (it is true that) I commit myself to take care, then (it is true that) you should not worry" that we interpret their utterances of "I promise I'll take care" and "Don't worry" as a single speechact - namely, an act of arguing. Normally, the fact that the speaker has used some epistemic modal (like "probably," "necessarily," "presumably," etc.) or an illative expression like "so," "therefore," "since," "consequently," etc. is what authorizes us to interpret the speaker's performance as a speech-act of arguing. Very roughly, the idea is that, illocutionarily, acts of arguing, so characterized, count as attempts at showing a target-claim to be correct. To the extent that they succeed in this - which means that the target-claim has been correctly qualified by a certain epistemic modal (semantic conditions) and that the act of arguing is a good means for showing this (pragmatic conditions) - they will be deemed good argumentation.

In order to determine whether a target-claim has been correctly qualified, we have to build arguments. That is, in LNMA arguments are mere representations of the particular inferences that supervene on acts of arguing and on acts of reasoning (i.e., particular inferential processes that are the mental counterparts of acts of arguing). In contrast with acts of arguing and acts of reasoning, which are, so to speak, 'objects' of the world, arguments are constructions, not abstract eternal objects from a Platonic world. From this perspective, we would not use arguments, but produce them in order to represent the inferences that we make.

As such, arguments can be obtained by displaying a variety of models, such as those of the different formal systems or informal argumentative schemas. For its part, LNMA adopts Toulmin's model of argument (Toulmin, 1958), because its underlying conception of material inference matches the analysis of argumentation that the SAS for the speech act of arguing provides (BermejoLuque, 2011, chap. 3). Accordingly, LNMA follows Toulmin's intuition that modal qualifiers are key to the semantic appraisal of argumentation. Yet, in contrast with Toulmin's model, LNMA's model of argument incorporates two types of modals: ontological and epistemic. 
In everyday discourse, we can make explicit the variety of ways in which we can put forward a certain semantic content $p$ in a firstorder constative speech-act by saying, for example " $p$ is true," " $p$ is (more or less) probable," " $p$ is (more or less) acceptable," " $p$ is (more or less) verisimilar," " $p$ is plausible," " $p$ is necessary," " $p$ is possible," etc. By so doing, we make another type of second-order speech-acts (Frápolli, 2012, p. 129). These ontological modals are terms that make explicit the type and degree of the pragmatic force of the constatives comprising an act of arguing. They are ontological because they are meant to express the value of our propositions as representations of the actual state of the world. When we put forward a propositional content with the appropriate pragmatic force given the actual state of the world, we make first-order constatives that are semantically correct-like the correct assertions "(it is true that) snow is white," "(it is necessary that) a bachelor is an unmarried man," "(it is plausible that) there is life on other planets," etc. Contrastingly, the modal that expresses the pragmatic force with which we draw a conclusion is an epistemic modal. This modal is meant to communicate what we take to be our credentials for concluding, that is, the type and degree of support that our reasons are supposed to confer on our target-claims because of our inference-claims. For example, in saying that a claim holds truly, necessarily, possibly, plausibly, (more or less) probably, etc. (i.e., in saying things such as "certainly $p$," "necessarily $p$," "it might be the case that $p$," "plausibly $p$," "(more or less) probably $p$," etc.), we are expressing something about the status of this claim as knowledge, about the confidence that we may place on it. Thus, any second-order speech-act of concluding involves, either explicitly or implicitly, not only the ontological modal of the firstorder constative that it is built on, but also the epistemic modal that indicates the force with which this first-order claim is concluded.

As representations of the inferences that supervene on acts of arguing and acts of reasoning, arguments in LNMA consist of the following elements: premises (corresponding either to the speechact of adducing a reason, $R$, or to the cognitive input in the act of reasoning, $C I$ ), conclusion (corresponding either to the speech-act of concluding a target-claim, $C$, or to the cognitive output in the 
act of reasoning, $\mathrm{CO}$ ), warrant (corresponding either to the inference-claim in the act of arguing, $I C$, or to its counterpart in the act of reasoning; i.e., the inference-motivation, $I M$ ) and the representations of the epistemic and ontological modals, em and om, of each of the speech-acts making up the act of arguing (corresponding to the type and degree of constative pragmatic force with which the speaker, either implicitly or explicitly, puts forward the propositional content of each constative) or of the judgments and beliefs constituting the act of reasoning (corresponding to the type and degree of assent to each propositional content constituting the act of reasoning). Thus, an ascription of both epistemic and ontological modals (ultimately, the ascription made by the arguer or the reasoner, which, in case she does not make them explicit, is something that we will have to infer from the context) is part of the layout of arguments, and the semantic appraisal of an act of arguing or reasoning results in the process of determining the right ascription of modals to each represented claim or judgement/belief (i.e., the process of ascertaining whether or not the ascription made by the arguer or the reasoner is correct after all). This model of argument can then be outlined as follows:

$\left(\mathrm{om}_{\mathrm{r} / \mathrm{i})}\right)$ Premise therefore $\left(e m_{*}\right)\left(o m_{c} / c o\right)$ Conclusion

\section{since \\ (omic/im)Warrant: "if $\mathrm{R} / \mathrm{Cl}$, then $\mathrm{C} / \mathrm{CO}$ "}

(The contents of the antecedent and the consequent of the warrant correspond to the whole first-order constatives $\mathrm{R}$ and $\mathrm{C}$ of the act of arguing, i.e., to their propositional contents in conjunction with their [implicit or explicit] ontological modals, or to the whole cognitive input and output, $\mathrm{CI}$ and $\mathrm{CO}$ of the act of reasoning, i.e., to their propositional contents and their corresponding type and degree of assent).

Let $\varphi$ represent the idiomatic function that, for each ontological modal of a conditional, assigns the epistemic modal needed to draw a conclusion having this conditional as its warrant; or, in other words, the term that is used in a certain language for express- 
ing either the pragmatic force of any speech-act of concluding having a conditional so qualified as its inference-claim, or the type and degree of assent to the cognitive output having a conditional so qualified as its inference-motivation.

$$
\varphi\left(\mathrm{om}_{\mathrm{i}}\right)=\mathrm{em}_{\mathrm{i}}
$$

In this account, an argument is valid (i.e., the inference is good, whatever its type) iff emi $=\mathrm{emx}$ and omi is correct — that is, if it is the ontological modal that actually corresponds to the inferenceclaim as a constative or to the inference-motivation as a belief or judgement, given the actual state of the world. In other words, an argument is valid if and only if the epistemic modal that the speaker (or reasoner) has used for concluding or coming to believe the cognitive output is the epistemic modal that $\varphi$ assigns to the ontological modal of the speaker's implicit inference-claim or inference-motivation, and this ontological modal is appropriate for this inference claim or inference motivation given the actual state of the world.

In LNMA, deductive arguments are arguments representing acts of arguing or acts of reasoning whose inferenceclaims/inference-motivations are meant to be necessary truths (like "if this is red, then it is coloured"). We know that an inferenceclaim or inference-motivation is meant to be necessary because the conclusion was drawn with such epistemic pragmatic force. In case this conditional is a necessary truth indeed, the argument will be valid, and the arguer will be entitled to epistemically qualify the conclusion with a "necessarily." For example, pieces of argumentation such as "She is in the garden or in the living-room, and she is not in the garden; so, necessarily she is in the living-room" or "This may be red; so, necessarily, it may be coloured" are deductive and valid because their corresponding inference-claims are the necessary truths "if (it is true that) she is in the garden or in the living-room, and (it is true that) she is not in the garden, then (it is true that) she is in the living-room" and "if (it is possible that) this is red, then (it is possible that) it is coloured." Likewise, valid probabilistic arguments will be those representing acts of arguing, or acts of reasoning, whose inference-claims/inferencemotivations are meant to be (more or less) probable so that they 
entitle us to epistemically qualify their conclusions with a "(more or less) probably/likely." For example, "Our currency is losing value; so, very probably, the inflation rate will rise" has as its inference-claim "if (it is true that) our currency is losing value, then (it is true that) the inflation rate will rise," which is very probable indeed (and makes the argumentation inductively valid).

Because LNMA deals with inferences as kinds of doings, it allows for an inference to be invalid and still be, for example, a deductive inference. Specifically, in LNMA, validity is not the same as deductiveness: "deductive," "inductive," "conductive," "abductive," "presumptive," etc. are names for types of inferences (i.e., forms of inferring), and any of them may go wrong.

\section{Evaluative deductivism}

LNMA deals with arguments as reconstructions of the inferences that we make in arguing and reasoning. On the other hand, it characterizes deductiveness in terms of the way in which the speaker or reasoner epistemically qualifies their conclusion, and it characterizes validity as a matter of the correctness of the corresponding inference-claim or inference-motivation. Thus, LNMA also provides an account of the distinction between deductiveness and validity. As a consequence, LNMA is able to make sense of the two intuitions underlying conditionals D and D', as pointed out in section 2. In turn, by means of LNMA's particular account of deductiveness and the theory of interpretation and reconstruction that this model involves, we can have a fair representation of what individuals mean when they reason or argue without rendering deductive all of their inferences. Consequently, by modus tollens, I have indirectly shown that evaluative deductivism is wrong.

Unfortunately, I think this is the most we can do as regards showing that evaluative deductivism is wrong, because, as pointed out in section 1, this thesis is but a basic intuition on what 'follows' means. In the remaining sections of this paper, I would like to explain, in turn, what is wrong with evaluative deductivism so understood.

Evaluative deductivists endorse the intuition that for an inference to be good, its conclusion cannot be false if the conjunction 
of its premises is true. But how do we establish what the actual set of premises of an inference is if, as we have seen, interpretative deductivism requires that we add whatever premises are needed in order to precisely warrant this? No doubt, rendering inferences deductive by including the associated conditional as a premise may be a functional strategy for evaluation: by doing so, we can "discover" where the eventual failure of the argument lies. As we have seen, there is no problem in reconstructing inferences as deductive in order to appraise them. The worst thing we can say about this kind of weak interpretative deductivism is that, because it turns any inference into a good one-for example, an instance of modus ponens - it does not seem a good strategy to determine whether or not a certain inference is good after all. Actually, the deductivist strategy only works for assessing inferences as a whole; according to this strategy, bad inferences are bad because, despite being deductive, they include one or more unacceptable or false premises.

For its part, LNMA also deals with the evaluation of inferences in terms of the evaluation of the claims that inferences consist of. In LNMA, we reconstruct inferences by means of a theory of interpretation that does not require us to put in the speaker's mouth anything else but the first order constatives that they made in their act of arguing, including the implicit inference-claim. An obvious advantage of this method is to avoid the dilemma of being either too strict or too charitable in our reconstructions. All that we need to represent an inference is being able to understand it as involving the propositional content that has been adduced (i.e., the reason or set of premises) and the propositional content that has been drawn from it (i.e., the conclusion). Once we have these constatives, we also have the implicit inference-claim, and all we have to do is to check whether or not all of them have been correctly qualified, just as interpretative deductivism maintains. Yet, because LNMA distinguishes between premises and inference-claims, it is also able to distinguish between overall inference goodness and validity.

Alternatively, we can understand evaluative deductivism as the view that for an inference to be good, the conclusion has to follow of necessity from the premises. As we have seen, in LNMA this amounts to requiring the conclusion to be advanced with a "neces- 
sarily" and the corresponding inference-claim or inferencemotivation to be a necessary truth. Yet why should we require the conclusion to be advanced with a "necessarily" and not with any other epistemic modal? As we have seen, LNMA allows us to epistemically qualify our conclusions in a variety of ways, which correspond to a variety of types of inferences different from deduction, and it explains what it means to say that such inferences are good. From this point of view, deductivism would simply look extravagant.

However, evaluative deductivism has, no doubt, a significant appeal. As Johnson put it,

According to some, the strongest argument for deductivism is its solid theoretical development. (...) the desirability of having an objective evaluation of argument is, historically, one of the considerations that has led theorists to opt for it. It is not just that there is the possibility of objective evaluation but as well the belief that arguments can settle (philosophical and other) issues once and for all ....conclusively" (Johnson, 2011, p. 23).

As Johnson observes, theories of inductive strength do not get the consensus that theories of deductive support get. This is why, deductivists such as Musgrave contended that "the only valid arguments are deductively valid arguments, and that deductive logic is the only logic that we have or need. The deductivist ploy regarding so-called non-deductive or inductive or ampliative arguments is to recast them as deductive enthymemes with unstated or missing premises of one kind or another" (Musgrave, 2012, p. 125). So, what is so good about modus ponens and other schemas of deductively valid arguments? The obvious answer is that they settle the highest epistemic standard for inference. After all, the requisite that the conclusion cannot be false if the conjunction of the premises is true makes inferring an utterly safe tool for getting new beliefs.

However, such requirement invites us to think what "cannot" actually means here. Consider this example of an alleged deductively valid argument by Shecaira:

During an election year, you cannot trust a politician who provides an optimistic prediction about a social problem that his party vowed to solve. 
Jones, a member of the labor party running for re-election this year, says that unemployment rates will go down.

You cannot trust Jones on this (2018, p. 477).

Shecaira defends what he calls a methodological deductivism and offers this kind of example in order to explain the benefits of supplying as many premises as needed for producing deductive argumentation whenever it is possible. He claims that by doing so, speakers make their argumentation more easily scrutable, which I think is true. However, it is far from easy to render deductive a piece of argumentation by adding more information. Going back to Shecaira's own example: is it really impossible that the premises of this argument are true and yet the conclusion is false? What about if Jones is under oath or is a close friend of the addressee, for example? Most of the times, non-monotonicity can only be redeemed by adding as a premise the associated conditional.

Consider also this example by Musgrave:

[If $a$ and $b$ share property $P$, and $a$ also has property $Q$, then it is reasonable to conjecture that $b$ also has property $Q$.]

$a$ and $b$ share property $P$.

$a$ also has property $Q$.

Therefore, it is reasonable to conjecture that $\mathrm{b}$ also has property $Q(2009$, $\mathrm{p}$. 224).

Again, what about if $\mathrm{b}$ also has property $\mathrm{R}$, which is incompatible with Q? My point with these examples is to show that unless we render inferences formally valid, it is difficult to render them deductively valid. ${ }^{1}$ This is why deductivism is typically associated with a defense of formal deductive logic (Johnson, 2000, chapter 3 ); playing by the rules of formal deductive logic seems to warrant that if our premises are true, our conclusion cannot be false.

However, formal-logical deductivism needs to prescribe rules of inference that cannot be justified in turn. They are supposed to be self-evident; yet, as Vann McGee (1985) pointed out, even modus ponens has counterexamples. Contrastingly, in LNMA, inferential normativity is a matter of the constitutive conditions of the

\footnotetext{
${ }^{1}$ LNMA explains this fact by pointing out that what makes an inference deductively valid is that its inference-claim or inference-motivation is a necessary truth. Only conceptual, mathematical, and formal truths seem the kind of truths that can be necessary.
} 
very practice of inferring. That the normativity of inferring is constitutive of the practice of arguing explains why people are usually good at inferring and at distinguishing between good and bad inferences even if they know nothing or very little about formal logic. Learning to infer amounts to mastering the use of epistemic modals, and much in the same way in which learning to make assertions involves learning what counts as making a good assertion, learning to infer is eo ipso learning what counts as inferring well.

Certainly, the idea that if things are as I say or believe, then my conclusion also has to be as I say or believe is a high epistemic standard for a conclusion. This standard enables us to determine inference wrongness independently of any other consideration or rule of inference that might be in need of justification itself. If the premises are true and the conclusion is false, there is something necessarily wrong with our inference.

In its own way, LNMA is also able to incorporate this standard. Assessing an inference according to LNMA is a matter of determining whether or not the ontological modal that the speaker attributes to the inference-claim is the one that it actually deserves. Accordingly, in LNMA, being good argumentation implies that if things are as the speaker adduces, the conclusion has to be as the speaker claims; and this standard holds not only for deductive inferences but also for any type of inference.

There is still one last move for the deductivist to make: to give up defending interpretative deductivism and contend that it is only good natural language argumentation that we have to interpret as being deductive. That would amount to refusing D and D' altogether. However, this is a difficult move for them to make. For, in principle, the procedure to render deductive a piece of argumentation is the same whether the argumentation or reasoning is good or bad. So, in order to contend that it is only good natural language argumentation and reasoning that must be reconstructed as being deductive, the deductivist must offer a reason (basically, a theory of interpretation) able to outlaw this procedure in the case of bad argumentation. Without this theory of interpretation, the prohibition to reconstruct bad argumentation as deductive can only be obeyed if we can intuitively recognize argumentation goodness without first recognizing deductiveness. Yet this view would go 
against the main intuition behind evaluative deductivism, which is that the essence of inference goodness is deductiveness.

The absence of a theory of interpretation also poses a problem for the use of formal logic as a tool to determine inference goodness. This is so because the use of formal logic requires the formalization of natural language argumentation and reasoning in accordance with the definition of well-formed formulae of the formal system to be used. That means that the selection of a particular formal system to appraise argumentation affects our verdict about its value: choosing two different formal systems may end up with contradictory verdicts. This is not a problem when systems are compatible with each other, like classical propositional logic and classical predicate logic; in those cases, the right verdict is the one that renders the inference valid - even though, as Gerald Massey (1975) observed, if no system renders the inference valid, we will not be allowed to say that it is invalid. But, what about if we choose systems that involve different notions of validity, as classical, intuitionistic, or paraconsistent logical systems do? As I argued in Bermejo-Luque (2009), in light of this quandary, we should rather say that formal logic does not serve to determine inference validity, but only to show that a given inference is/is not good according to one system or another. Contrastingly, an additional advantage of LNMA is that it does not rely on brute intuitions to reconstruct and assess argumentation and reasoning, but on an independent theory of meaning such as the Speech Act Schema for the act of arguing. By interpreting, in the sense of "understanding," what the subject said or thought, we obtain an argument that allows us to determine the goodness of her inference without the need to edit her words or thoughts.

\section{Conclusion}

The above considerations might give rise to the following questions. I hope I have provided the following responses:

1) Is LNMA's account of inference normativity different from or equivalent to that of deductivism? In LNMA, an inference is valid if its inference-claim or inference-motivation is correctly qualified (ontological modal qualifier), and it is a good inference if 
the conclusion is also correctly qualified (epistemic qualifier), which requires that the reason is correctly qualified too. In LNMA, validity is a matter of the correctness of a conditional regarding the actual world, not a matter of conforming to standards of inference. No doubt, deductivism has resources to turn any valid inference into a deductively valid argument. But most of the time it does so at the expense of dealing with inferential normativity as a matter of formal rules or axioms. Contrastingly, LNMA deals with inferential normativity as constitutive of the practice of inferring. As pointed out, the main advantage of a constitutive account of inferential normativity is that we do not need to appeal to the alleged self-evidence of formal rules or justify the obligation to follow them when inferring. In LNMA, counting as inferring-either in reasoning or arguing - amounts to counting as following the pragmatic constitutive rules of inferring, which involve endorsing a conditional in a certain way. In turn, assessing our success in so doing - that is, assessing our inferences - involves assessing this conditional and the rest of the propositions that we endorse by inferring and checking whether or not we are right in endorsing them with the pragmatic force with which we do so.

On the other hand, in LNMA 'follows from' allows for different standards. In fact, an additional advantage of LNMA is that it provides a general framework to characterize what all these standards have in common, which is the correctness of the corresponding conditionals. Thus, in Bermejo-Luque (2012, 2014), I have dealt with analogical reasoning as reasoning in which the conditional is supposed to be justified by means of an analogy (like in "A is F; therefore B is F"). In turn, in Bermejo-Luque (2016, 2019a), I argued that "presumably, p" is different from "p, I presume," and I gave a linguistic-pragmatic account of both in order to provide the correctness conditions for presumptive inferences. Finally, in (2019b) I explained that LNMA provides a general framework for plausible inferences and allows for the possibility of dealing with other types of inferences that are not normally taken into account (for example, those that regulate the use of 'truly' and 'possibly').

2) Is a speech-act account (or LNMA's account in particular) really necessary to deal with the notion of validity? No doubt, ar- 
guments as products consist of propositions. However, my contention is that we have arguments as products because we have inferences (i.e., reasonings and speech-acts of arguing where propositions are put forward with a certain pragmatic force, which is what makes them correct or incorrect, given the actual state of the world). We have an argument when someone puts forward a proposition as a reason for another claim, it is not that we know that someone is arguing or reasoning because she "used" an argument. Otherwise, we would never have a reason to say that someone is arguing badly instead of not arguing at all, because bad arguments are just sets of propositions, and "using a set of propositions" is something that we also do, for example, when we describe a landscape or tell a story.

3) Is LNMA really a tool to determine validity and argumentation goodness? What is the use of defining $\varphi$ ? As pointed out before, the main feature of LNMA is to deal with the normativity of inferring as resulting from the very practice of inferring. In particular, the idea is that competence in the use of epistemic modals involves ability to distinguish between good and bad inferences. But, at this point, the worry might be that LNMA succeeds at the expense of failing to be informative, because in order to use this model we must already have function $\varphi$. Contrastingly, my claim is that mastering the use of epistemic modals is mastering the distinction between good and bad inferences - or, in other words, that we already have the connection between epistemic and ontological modals, because this is no more than the meaning of the corresponding epistemic modals. This means that LNMA does not pretend to regulate the use of these modals but to provide their semantics as expressions of the pragmatic force that reasons confer on conclusions. It is because we know their meaning that we know whether a specific use of an epistemic qualifier is right or wrong and, therefore, whether an inference is good or bad. In this account, what we do when we assess an inference is to check whether the use of an epistemic modal is appropriate, which depends on the meaning of the epistemic modal in question and on our own view of how the world actually is. 


\section{Acknowledgements}

My deepest gratitude to David Godden for reading a first version of this manuscript and making the key questions to improve it. Thanks also to the two anonymous reviewers from Informal Logic for their helpful comments and suggestions.

\section{References}

Bach, K. \& R. Harnish. 1979. Linguistic communication and speech acts. Cambridge, MA: MIT Press.

Berg, J. 1987. Interpreting arguments. Informal Logic 9(1): 13-21.

Bermejo-Luque, L. 2009. Logic as (normative) inference theory: formal vs. non-formal theories of inference goodness. Informal Logic 28(4): 315-334.

(2011) Giving reasons: a linguistic pragmatic approach to argumentation theory. Dordrecht: Springer.

(2012) A unitary schema for arguments by analogy. Informal Logic 32(1): 1-24

(2014) Deduction without dogmas: the case of moral analogical argumentation. Informal Logic 34(3): 311- 336.

(2016) Being a correct presumption vs. being presumably the case. Informal Logic 36(1): 1-25.

(2019a) On the relationship between presumptions and burdens of proof. In Presumptions and burdens of proof. An anthology of argumentation and the law, eds. H. Hansen, F. Kauffeld, J. Freeman, and L. Bermejo-Luque. Tuscaloosa: University of Alabama Press

(2019b) The appraisal of conductions. Informal Logic 39(2): 123-145

Botting, D. 2016. The Logical evaluation of arguments. Argumentation 30(2): 167-180.

Carroll, L. 1895. What the tortoise said to Achilles. Mind 4(14): 278-280.

Castañeda, H. N. 1960. On a Proposed Revolution in Logic. Philosophy of Science 27(3): 279-292.

Copi, I. 1978. Contemporary philosophical logic. Nueva York: St. Martin's Press. 
Fohr, S. 1979. The deductive-inductive distinction. Informal Logic Newsletter 11(2): 5-8.

Frápolli, M. J. 2012. The nature of truth: An updated approach to the meaning of truth ascriptions. Dordrecht: Springer.

Godden, D. 2005. Deductivism as an interpretive strategy: A reply to Groarke's recent defense of reconstructive deductivism." $A r$ gumentation and Advocacy 41(3): 168-183.

Govier, T. 1992. What is a good argument? Metaphilosophy 23(4): 393-409.

Groarke, L. 1992. In defense of deductivism: Replying to Govier. In Argumentation Illuminated, eds. F.H. van Eemeren, R. Grootendorst, J. Blair and C. Willard, 113-121. Amsterdam: SicSat

Hitchcock, D. 1980. Deduction, induction, conduction. In Informal Logic Newsletter 3(2): 7-15

2017. On reasoning and argument: Essays in informal logic and on critical thinking. Dordrecht: Springer

Johnson, R. 2000. Manifest rationality. A pragmatic theory of argument. Mahwah, NJ: Lawrence Erlbaum.

2011. Informal Logic and Deductivism. Studies in Logic 4(1): 17-37.

Machina, K. 1985. Induction and deduction revisited. Nous 19(4): 571- 578.

Massey, G. 1975. Are there good arguments that bad arguments are bad? Philosophy in Context 4: 61-77. Reprinted in H.V. Hansen and R. C Pinto (1995). Fallacies: Classical and Contemporary Readings. The Pennsylvania State University Press, Pennsylvania.

McGee, V. 1985. A counterexample to modus ponens. Journal of Philosophy 82(9): 462-471.

Musgrave, A. 2009. Popper and hypothetico-deductivism. In Handbook of the History of Logic; Inductive Logic, Volume 10, eds. D. Gabbay, J. Woods and A. Kanamori, 206-234. Elsevier. 2012. Deductivism surpassed: Or, foxing in its margins?" in Journal of General Philosophy of Science 43(1): 125-132.

Shecaira, F. 2018. The value of methodological deductivism in argument construction. Informal Logic 38(4): 471-501. 
Toulmin, S. E. 1958. The uses of argument. Cambridge: Cambridge University Press.

Vorobej, M. 1992. Defining deduction. Informal Logic 14(2\&3): 105-118. 